\title{
Pengolahan Data Pengiriman Buah Kelapa Sawit PTPN IV Balimbingan Menuju Pabrik PKS Dosin
}

\author{
Elisabet Pasaribu1, Widodo Saputra ${ }^{2}$, Imam A. Batu Bara ${ }^{3}$, Ida Wulandari ${ }^{4}$ \\ Mahasiswa Prodi ManajemenInformatika ${ }^{1,3,4}$,StaffPengajar Prodi manajemenInformatika ${ }^{2}$. \\ AMIK Tunas BangsaPematangsiantar
}

\begin{abstract}
Along with the development of an all-modern era, and the increasingly advanced information technology today has created increasingly fierce competition in almost all aspects of life both in every company and institution must adapt to technological developments. To be able to improve the performance of employees in completing work in the field of data processing of shipping oil palm fruit this system is needed to help the work of the employees on duty. Based on observations (observations) made at PT. Perkebunan Nusantara IV Business Guidance Unit, in improving the process of sending oil palm fruit to PKS Dosin needs to be managed with a good and professional system in order to produce an administrative function of the company. Therefore special attention needs to be made to make it easier to process data transmission, data search and data reporting as needed quickly, precisely and accurately using Tables, RATs, DFD, ERD, Flowcharts and Interface designs. After the design is complete this system will be built using Adobe Dreamweaver CS 6 Software and MySQI Database. This system can simplify the Processing of Data on Palm Oil Fruit Delivery Towards the Dosin MCC Mill.
\end{abstract}

Keyword: Data Processing of Oil Palm Fruit Delivery, Adobe Dreamweaver CS 6, XAMPP

Abstrak- Seiring dengan perkembangan jaman yang serba modern, dan semakin majunya teknologi informasi sekarang ini telah menciptakan persaingan yang semakin ketat hampir diseluruh aspek kehidupan baik dalam setiap perusahaan maupun instansi harus beradaptasi dengan perkembangan teknologi. Untuk dapat meningkatkan kinerja dari karyawan dalam menyelesaikan pekerjaan dibidang pengolahan data pengiriman buah kelapa sawit sistem ini dibutuhkan untuk membantu pekerjaan karyawan yang bertugas. Berdasarkan pengamatan (observasi) yang dilakukan di PT. Perkebunan Nusantara IV unit Usaha Balimbingan, dalam meningkatkan proses pengiriman buah kelapa sawit menuju PKS Dosin perlu dikelolah dengan sistem yang bagus dan profesional agar menghasilkan suatu fungsi administrasi perusahaan. Oleh karena itu perlu mendapat perhatian khusus mempermudah pengolahan data pengiriman, pencarian data dan pelaporan data sewaktu diperlukan dengan cepat, tepat dan akurat dengan menggunakan Tabel, RAT, DFD, ERD, Flowchart dan rancangan Interface. Setelah perancangan selesai sistem ini akan dibangun dengan menggunakan Software Adobe Dreamweaver CS 6 serta Database MySQl. Sistem ini dapat mempermudah Pengolahan Data Pengiriman Buah Kelapa sawit Menuju Pabrik PKS Dosin.

Kata Kunci: Pengolahan Data Pengiriman Buah Kelapa Sawit, Adobe Dreamweaver CS 6, XAMPP.

\section{PENDAHULUAN}

PT. Perkebunan Nusantara IV adalah bekas Badan Usaha Milik Negara Indonesia (BUMN) yang bergerak dibidang perkebunan kelapa sawit dan teh yang mencakup pengolahan areal tanaman, kebun bibit dan pemeliharan tanaman. 
Selama ini dalam pengiriman buah kelapa sawit pada PT. Perkebunan Nusantara IV unit Usaha Balimbingan masih menggunakan cara manual, yaitu dengan menggunakan media kertas, tidak adanya aplikasi khusus untuk mengolah data pengiriman buah kelapa sawit. Menyebabkan proses pengiriman buah kelapa sawit menjadi sulit, seperti proses pengiriman buah kelapa sawit, penginputan data, mencari data sawit yang telah dikirim, serta lambatnya proses pelaporan pengolahan data pengiriman buah kelapa sawit. Menyebabkan proses pengiriman buah kelapa sawit menjadi sulit, seperti proses pengiriman buah kelapa sawit, penginputan data, mencari data sawit yang telah dikirim, serta lambatnya proses pelaporan pengolahan data pengiriman buah kelapa sawit pada PTPN IV unit Usaha Balimbingan. meningkatkan proses pengiriman buah kelapa sawit menuju PKS Dosin perlu dikelolah dengan sistem yang bagus dan profesional agar menghasilkan suatu fungsi administrasi perusahaan. Oleh karena itu perlu mendapat perhatian khusus mempermudah pengolahan data pengiriman, pencarian data dan pelaporan data sewaktu diperlukan dengan cepat, tepat dan akurat dengan menggunakan pemrograman Adobe Dreamweaver dan Database MySql. Tujuan dari paper ini adalah untuk proses pencarian data dan penginputan data dapat berlangsung secara sistematis, dapat menampung seluruh file yang ada dengan kapasitas yang besar dan pengiriman buah kelapa sawit menuju Pabrik PKS Dosin agar dapat terselesaikan secara tepat,cepat dan akurat.

\section{METODOLOGI PENELITIAN}

Didalam tinjauan pustaka akan menguraikan secara sistematik hasil-hasil penelitian ini akan menerangkan secara teoritis tentang dasar-dasar teori yang menjadi masalah sesuai dengan judul yang diangkat, menguraikan tentang sejarah perusahaan, struktur organisasi, visi dan misi, bagaimana prosedur pengiriman buah kelapa sawit yang baik ke Pabrik PKS Dosin.

\subsection{Pengertian Pengolahan Data}

Menurut Sutabri, 2012 [1] " Pengolahan data merupakan bahan mentah untuk di olah yang hasilnya kemudian menjadi informasi. Dengan kata lain, data yang telah di peroleh harus di ukur dan di nilai baik dan buruk, berguna atau tidak dalam hubungannya dengan tujuan yang akan di capai".

\subsection{Data}

Menurut Sutabri, 2012 [1] Data adalah fakta mengenai objek data juga dapat didefenisikan sebagai bahan keterangan tentang kejadian-kejadian atau fakta yang dirumuskan dalam sekelompok lembaga tertentu yang tidak di acak yang menunjukan jumlah, tindakan, kejadian, aktivitas dan transaksi yang tidak mempunyai makna atau tidak berpengaruh secara lansung kepada pemakai.

\subsection{Database}

Menurut Jogiyanto, 2005 [4] 'Basis data ( database ) merupakan kumpulan dari data yang saling berhubungan satu dengan yang lainnya, tersimpan di perangkat keras komputer dan digunakan perangkat lunak untuk 
memanipulasinya'. Database merupakan basis dalam menyediakan informasi bagi para pemakai.

\subsection{Bahasa Struktur Query Language (SQL)}

SQL (Structured Query Language) adalah bahasa non procedural untuk mengakses data pada database relasional. SQL adalah bahasa database yang dipergunakan dalam menyelesaikan permasalahan dalam database serta mempunyai kelebihan dalam mengolah data. Standar SQL mula-mula didefenisikan oleh ISO (International Standards Organization) dan ANSI (the American National Standards Institute) yang dikenal dengan sebutan SQL86 [2].

\subsection{Pengenalan Adobe Dreamweaver CS6}

Dreamweaver adalah sebuah editor professional yang mengunakan HTML untuk mendesain web secara visual dan mengelola situs atau halaman web (Elcom, 2013).

\subsection{Entity Relationship Diagram (ERD)}

Entity Relationship Diagram (ERD) memiliki dua komponen utama yaitu Entitas (Entity) dan Relasi (Relation). Kedua komponen ini ,masing-masing dilengkapi dengan sejumlah atribut yang mempresentasikan seluruh fakta yang ada di dunia nyata. ERD ini dapat digambarkan secara sistematis dengan menggunakan simbol-simbol seperti yang terlihat pada tabel 2.2. [2]

\subsection{Data Flow Diagram (DFD)}

Data Flow Diagram adalah suatu network yang menggambarkan suatu system automat/komputerisasi, manualisasi atau gabungan dari keduanya yang penggambarannya disusun dalam bentuk komponen sistem yang saling berhubungan sesuai dengan aturan mainnya".[3]

\section{HASIL DAN PEMBAHASAN}

\subsection{Perancangan}

\subsubsection{Perancangan ERD}

Bentuk dari Entity Relational Diagram dari Pengolahan Data Pengiriman Buah Kelapa Sawit PTPN IV Balimbingan Menuju Pabrik PKS Dosin. 


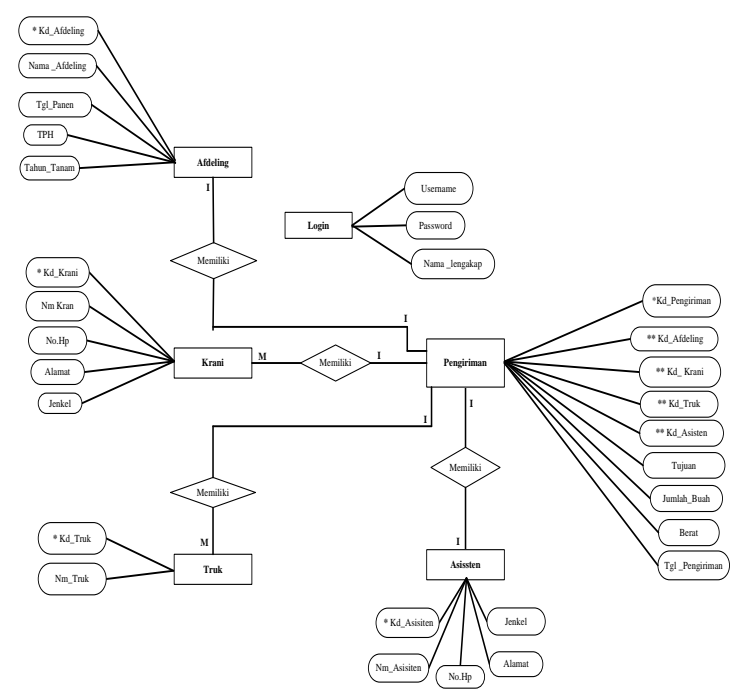

Gambar 1. ERD Database Pengiriman

\subsubsection{Perancangan RAT}

Berikut ini merupakan tampilan RAT yang menghubungkan antara satu tabel dengan tabel yang lain sesuai dengan kondisi primary key dan foreign key. Seperti gambar berikut ini :

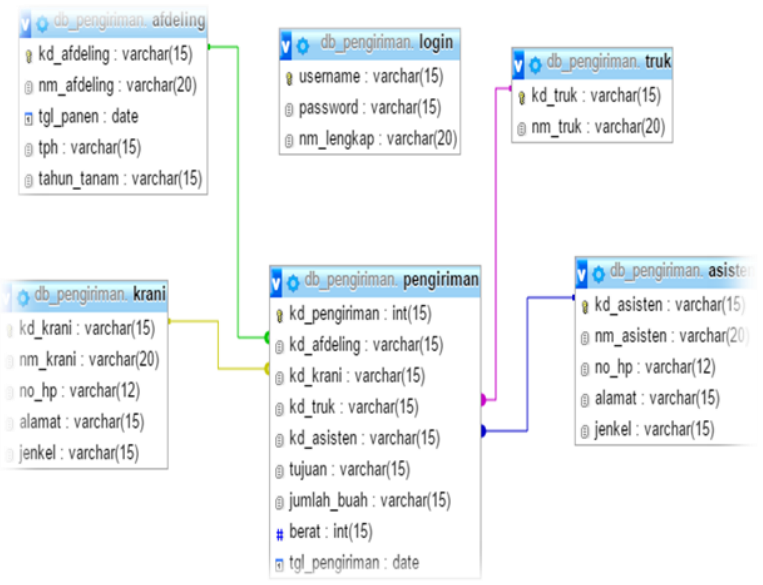

Gambar 2. RAT Database Pengiriman

\subsubsection{Perancangan DFD}

a. DFD Level 0

Adapun perancangan DFD level 0 Pengolahan Data Pengiriman Buah Kelapa Sawit PTPN IV sBalimbingan Menuju Pabrik PKS Dosin adalah seperti gambar 3.berikut ini. 


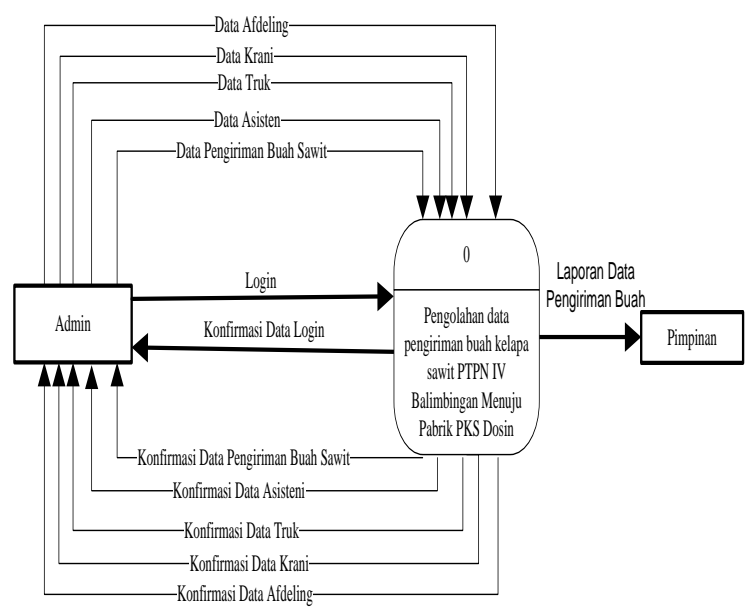

Gambar 3.DFD Level 0

b. DFD Level 1

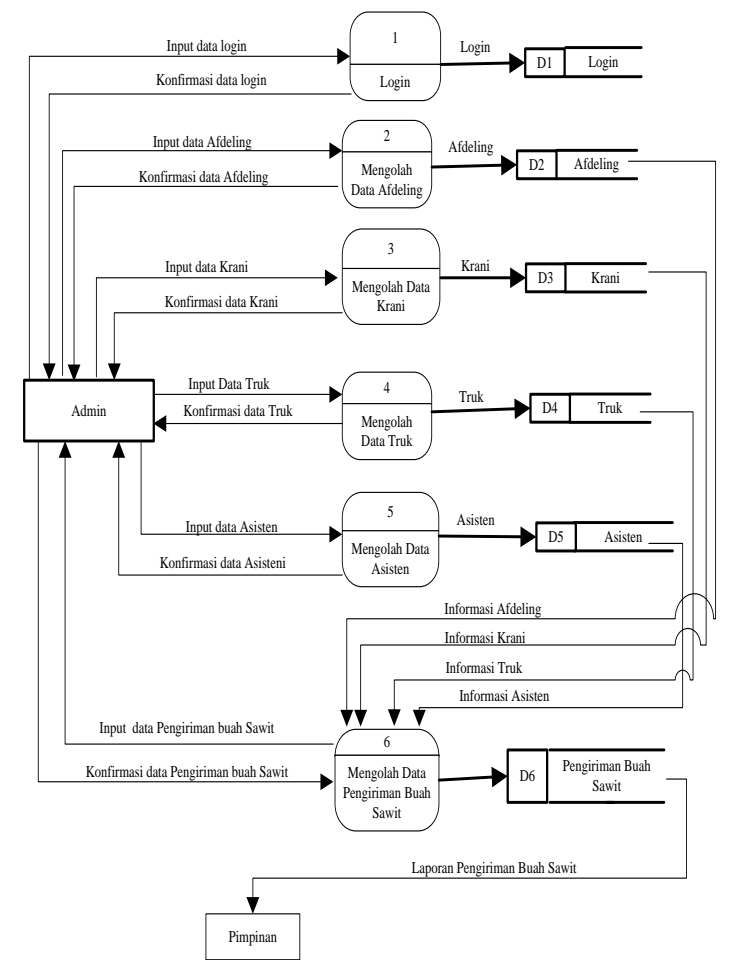

Gambar 4. DFD Level 1.

\subsection{Implementasi}

\subsubsection{Halaman Utama}

Halaman dashboard/beranda merupakan tampilan awal website ketika admin pertama kali mengakses halaman web. 


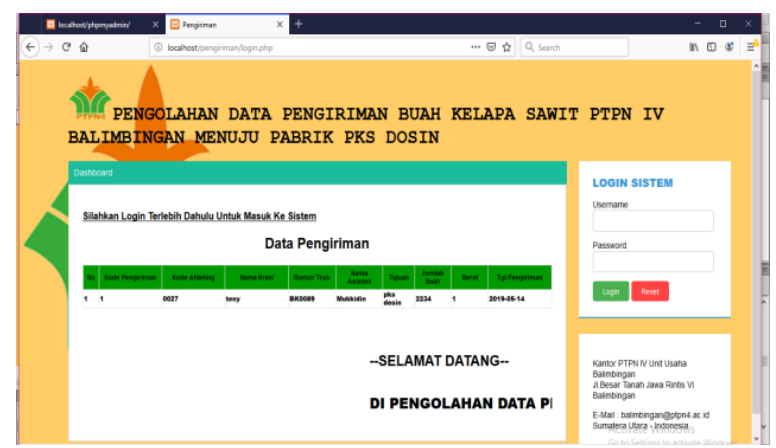

Gambar 5.Rancangan Form Utama

\subsubsection{Halaman Login}

Menu Login digunakan oleh administrator khusus untuk melakukan login

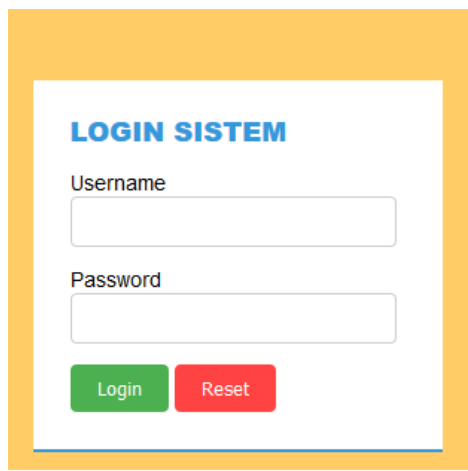

Gambar 6.Rancangan Form Login

\subsubsection{Halaman Home Admin}

Halaman home admin merupakan halaman yang tampil pertama kali sewaktu admin telah melakukan proses login. Berikut ini tampilan halaman home admin lihat pada gambar 4.3.

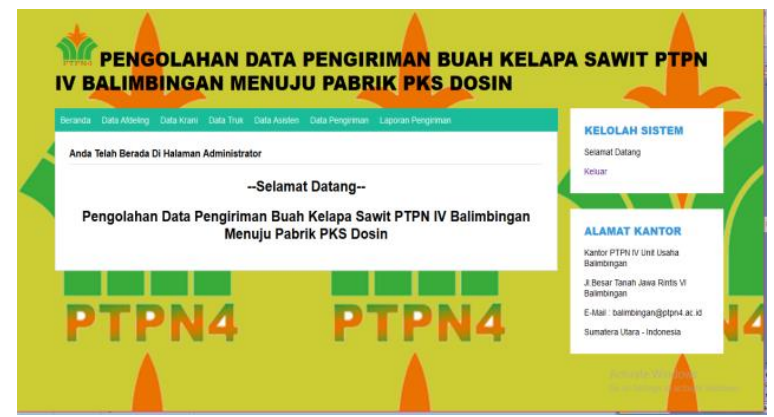

Gambar 7. Halaman Home Admin

\subsubsection{Halaman Afdeling}

Halaman Input Data Afdeling digunakan oleh administrator untuk menginput data afdeling di PTPN IV Balimbingan. Tampilan halaman input data afdeling dapat dilihat pada gambar 4.4. 


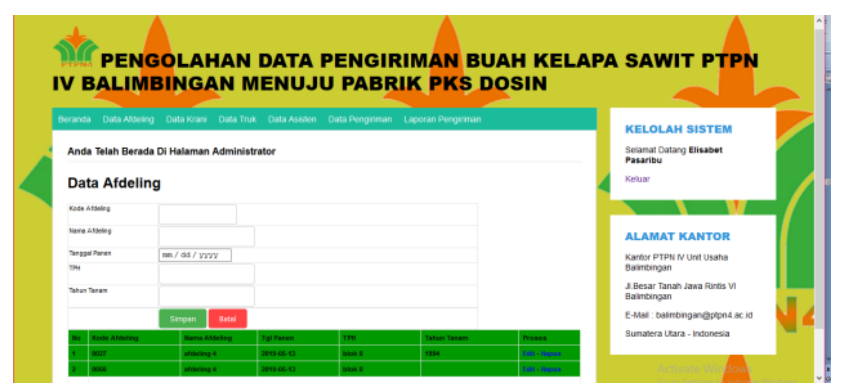

Gambar 8. Tampilan Halaman Input Data Afdeling

\subsubsection{Halaman Krani}

Halaman Input Data Krani digunakan oleh administrator untuk menginput data krani di PTPN IV Balimbingan. Tampilan halaman input data krani dapat dilihat pada gambar 4.5.

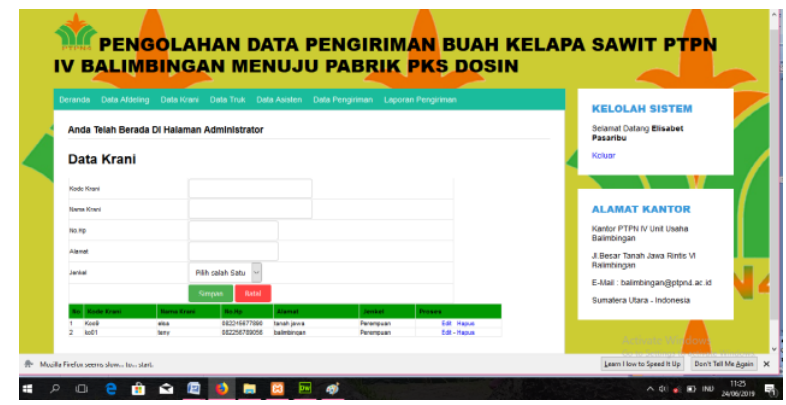

Gambar 9.Rancangan Form Krani

\subsubsection{Halaman Truk}

Halaman Input Data truk digunakan oleh administrator untuk menginput data truk di PTPN IV Balimbingan. Tampilan halaman input data truk dapat dilihat pada gambar 4.6.

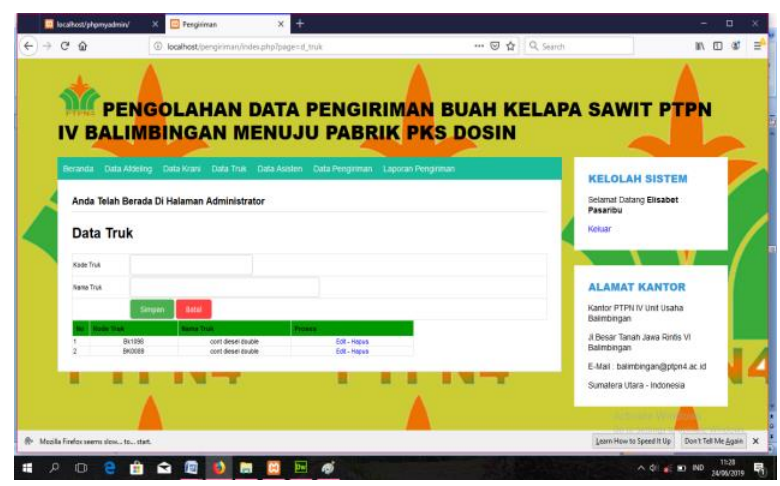

Gambar 10. Rancangan Form Truk

\subsubsection{Halaman Asisten}

Halaman Input Data Asisten digunakan oleh administrator untuk menginput data asisten di PTPN IV Balimbingan. Tampilan halaman input data asisten dapat dilihat pada gambar 4.7. 


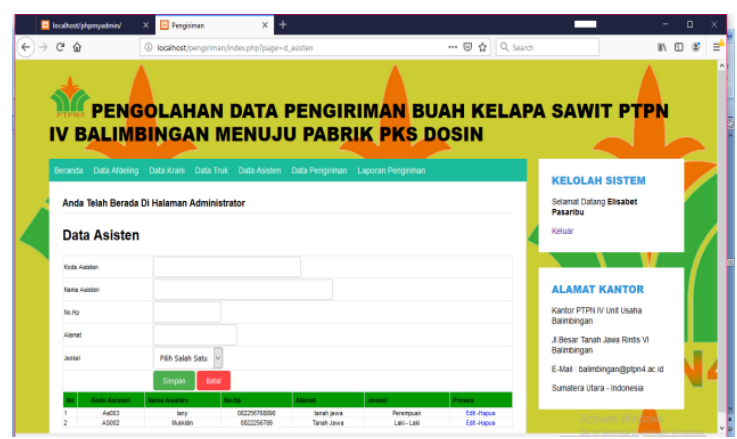

Gambar 11. Rancangan Form Asisten

\subsubsection{Halaman Laporan Pengiriman}

Halaman Input Data pengiriman digunakan oleh administrator untuk menginput data di PTPN IV Balimbingan. Tampilan halaman input data pengiriman dapat dilihat pada gambar 4.8 .

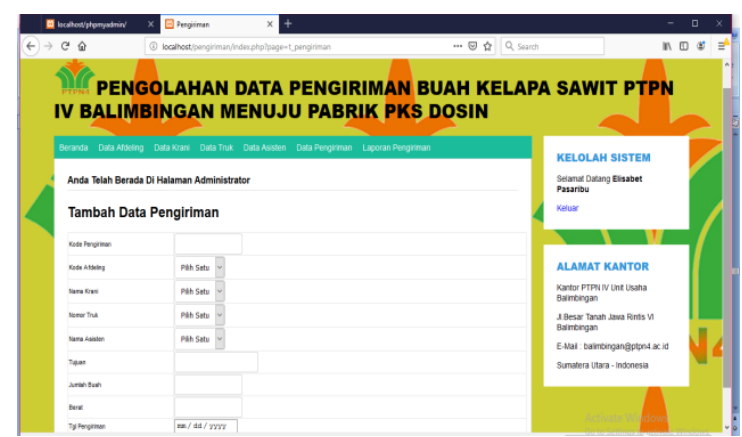

Gambar 12. Rancangan Form Pengiriman

\subsubsection{Laporan Halaman Browse dan Cetak Laporan}

Berikut ini adalah halaman browse dan cetak laporan data pengiriman buah kelapa sawit, adapun tampilannya dapat dilihat pada gambar 4.9.

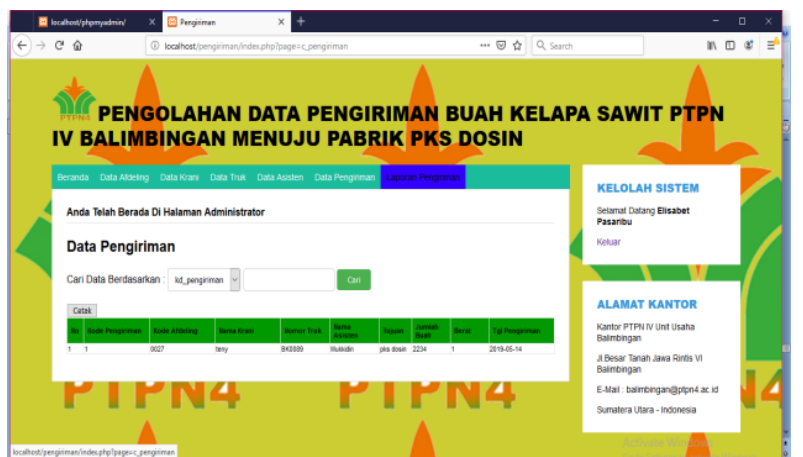

Gambar 13. Rancangan Form Browse dan Halaman Cetak Laporan

\subsubsection{Laporan Hasil Cetak Laporan}

Halaman hasil cetak laporan sebagai laporan transaksi data pengiriman buah kelapa sawit yang dapat dicetak dari data yang telah di input. Tampilan halaman cetak laporan dapat dilihat pada gambar 4.10. 


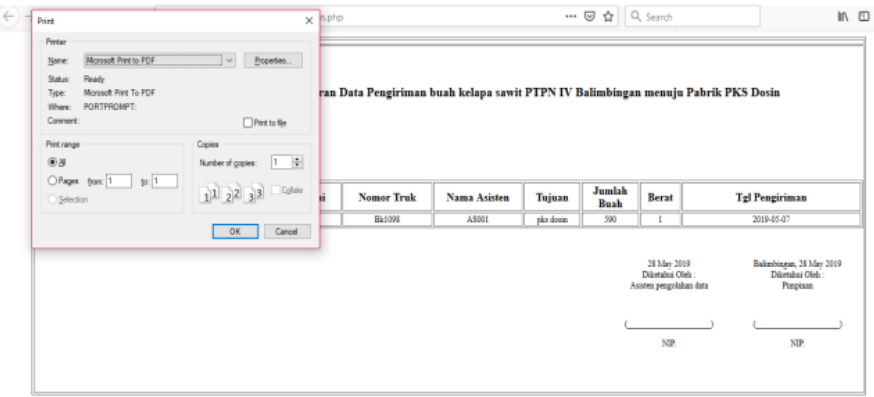

Gambar 14. Rancangan Form Hasil Cetak Laporan

\section{Kesimpulan}

Pengolahan data pengiriman buah kelapa sawit PTP IV balimbingan menuju pabrik PKS dosin ini dibangun dengan menggunakan Adobe Dreamweaver CS6 dan database MySQL. Sistem ini dapat membantu dalam mengefisienkan waktu dimana pengolahan datanya terintegrasi sehingga dalam waktu pengiriman buah kelapa sawit menjadi lebih cepat dan akurat. Memberikan kemudahan kepada pegawai dalam mengetahui informasi pengiriman buah kelapa sawit PTP IV balimbingan menuju pabrik PKS dosin.

Beberapa saran yang dapat penulis berikan yang kiranya dapat diimplementasikan demi meningkatkan proses kinerja Sistem ini diantaranya :

1. Menjaga kerahasian akun, demi terjaganya rahasia Data Pengguna di dalam Sistem.

2. Program ini masih mempunyai keterbatasan sistem informasi ini kedepannya diharapkan dapat dikembangkan lagi agar dapat memenuhi kebutuhan dan fungsi terbaru dalam pengolahan data pengiriman buah kelapa sawit PTPN IV balimbingan menuju pabrik PKS Dosin.

3. Untuk selanjutnya, sebaiknya sistem informasi ini dikembangkan dengan menggunakan bahasa pemrograman yang lebih up to date, agar sistem ini dapat dapat berkembang seiring dengan kemajuan teknologi.

\section{DAFTAR PUSTAKA}

[1]Abdurahman, M. (2018). Sistem Informasi Data Pegawai Berbasis Web Pada Kementerian Kelautan Dan Perikanan Kota Ternate. Jurnal Ilmu Komputer Dan Informatika, 1(2), 70-78.

[2]Iswandy, E., Sekolah, D., Manajemen, T., Komputer, I., \& Balantai, B. (2015). Jurnal TEKNOIF ISSN : 2338-2724 SISTEM PENUNJANG KEPUTUSAN UNTUK MENENTUKAN PENERIMAAN MAHASISWA DAN PELAJAR KURANG MAMPU Vol . 3 No . 2 Oktober 2015 Jurnal TEKNOIF ISSN : 2338-2724, 3(2).

[3]Kusnady, D., \& Pd, S. (2018). Sistem Informasi Biaya Pendidikan ( BPP ) pada Politeknik Ganesha Medan Berbasis Web. Diding Kusnady, S. Pd, MM Ardiman Siregar Politeknik, 1, 9-13. https://doi.org/10.1016/j.tetlet.2009.12.072

[4]Setioardi, M. A., Lajmudin, A. B., \& Studi, K. P. (2018). Barang Inventaris Berbasis Web Pada Sma Negeri. Ahmad Khambali1, Agus Siswanto2, 5(1), 44-49

[5] M. Anggara, H. Sujiani, and H. Nasution, "Pemilihan Distance Measure Pada K-Means Clustering Untuk Pengelompokkan Member Di Alvaro Fitness," vol. 1, no. 1, pp. 1-6, 2016.

Pengolahan Data Pengiriman Buah Kelapa Sawit PTPN IV Balimbingan (Elisabet Pasaribu) | 954 